\title{
Symptomatic Urinary Lithiasis: Epidemiology and Management at Urology Department of University Hospital of Cotonou
}

\author{
Prince Pascal Hounnasso' ${ }^{1}$ Josué Dejinnin Georges Avakoudjo', Abdoul Karim Paré1*, \\ Kirakoya Brahima1, Adama Ouattara ${ }^{2}$, Michel Michael Agounkpé1, Gilles Natchagandé1, \\ Sanni Rafiou Toré1, Abubakar Babagana Mustapha ${ }^{3}$, Alexandre Vodounou ${ }^{1}$

\footnotetext{
${ }^{1}$ Department of Urology, Hubert Koutoucou Maga Teaching Hospital of Cotonou, Cotonou, Bénin

${ }^{2}$ Department of Urology, Souro Sanou Teaching Hospital of Bobo-Dioulasso, Bobo-Dioulasso, Burkina Faso

${ }^{3}$ Department of Surgery, Federal Medical Center, Nguru, Nigeria

Email: ${ }^{*}$ boupare@yahoo.fr
}

Received 24 November 2014; accepted 5 February 2015; published 6 February 2015

Copyright (C) 2015 by authors and Scientific Research Publishing Inc.

This work is licensed under the Creative Commons Attribution International License (CC BY).

http://creativecommons.org/licenses/by/4.0/

(c) (i) Open Access

\section{Abstract}

Purpose: To study the epidemiology and treatment modalities of urolithiasis at Urology Department of University Hospital of Cotonou. Materials and Methods: It was a retrospective and descriptive study over a 10 years period ranging from January 1st, 2004 to December 31st, 2013. One hundred and two patients who were hospitalized for symptomatic urolithiasis at the Urology Department of University Hospital of Cotonou were enrolled. Results: Hospital incidence of urolithiasis was $3.7 \%$. Patients mean age was 39.6 years (extremes: 10 years to 73 years). Male to female ratio was 2.2 . The main reason for consultation was renal colic for 81 patients $(79.4 \%)$. Average duration of symptoms at presentation was 5 months (range: 1 day to 10 years). A total of 173 stones were identified with an average size of $12 \mathrm{~mm}$ (range: $1 \mathrm{~mm}$ to $95 \mathrm{~mm}$ ). Calyceal stones were seen in $32.9 \%$ of cases, renal pelvis stones in $21.4 \%$ of cases, ureteral stones in $34.1 \%$ and bladder stones in $\mathbf{1 1 . 5 \%}$ of cases. Open surgery was the main treatment for stones that could not be managed medically. $50.8 \%$ of patients underwent surgery with extraction of 116 stones. This represented $67.1 \%$ of all stones. 9 patients $(8.8 \%)$ had expelled their stone during urination. The postoperative course was uneventful in $\mathbf{7 7 . 5 \%}$ of cases. Conclusion: Modern treatment options for urolithiasis remain rudimentary in our health facilities. Open surgery is still the main stay of treatment in our countries with limited resources.

"Corresponding author.

How to cite this paper: Hounnasso, P.P., et al. (2015) Symptomatic Urinary Lithiasis: Epidemiology and Management at Urology Department of University Hospital of Cotonou. Open Journal of Urology, 5, 7-12.

http://dx.doi.org/10.4236/oju.2015.52002 
Keywords

\section{Urolithiasis, Renal Calculi, Bladder Calculi, Epidemiology, Open Surgery}

\section{Introduction}

Urolithiasis is a stony concretion created by a cluster of crystalline or amorphous particles precipitated in the urine [1]. The epidemiological characteristics of urolithiasis have continued to evolve in recent years in response to changes in dietary habits, health conditions, environmental factors and the prevalence of diseases that predispose to the risk of nephrolithiasis (obesity, diabetes, metabolic syndrome etc.) [2]. Imaging is a vital contribution to the diagnosis. Despite the advent of endoscopy, which has become the gold standard treatment for most of the calculus in developed countries, open surgery remains the main stay in developing countries [3] [4]. No studies in Bénin have addressed the management of symptomatic urolithiasis. The aim of our study was to describe the epidemiology and treatment modalities for patients who were hospitalized at the Urology Department of University Hospital of Cotonou for symptomatic urolithiasis.

\section{Patients and Methods}

This was a retrospective and descriptive study of patients hospitalized for symptomatic urolithiasis in the department Urology Andrology of University Hospital of Cotonou between January 1st, 2004 to December 31st, 2013 (10 years). The studied sample consists of patients admitted with radiologically confirmed symptomatic urolithiasis.

The items studied were: age, sex, presenting complaints, history of presenting complaint, mode of admission, main presentation of complaints, examination findings and imaging results. Also considered number, size and location of the stone(s), presence of urinary tract infection and treatment given, pre and postoperative management of the patient, and length of hospital stay. Apro forma was designed to collect the data. Data were retrived from patients' medical records, operative register and hospital register. Data analysis was done by using EpiInfo 2012 version 3.5.4 French.

\section{Results}

During the study period of 10 years, 2748 patients were hospitalized, out of this, 102 patients (3.7\%) have radio logically confirmed symptomatic urolithiasis. The average age of the patients was 39.6 years (range: 10 to 73 years). Male to female sex ratio was 2.2. The age group of 31 to 45 has the highest frequency (Table 1).

One out of five patients (19.6\%) admitted in the year 2013 has radio logically confirmed urolithiasis. The overall incidence was 10.2 cases. The distribution of the patients who were confirmed with urolithiasis according the year of hospitalization is shown in Figure 1.

The presence of renal colic episode was found in 14 patients (13.7\%) and 5 patients (5\%) had undergone pelvic and/or abdominal surgery for urolithiasis. It was also found that $12.7 \%$ of the patients consume alcohol and $10.8 \%$ of the patients were hypertensive. Tobacco abuse and high consumption of milk or dairy foods were found in 2 patients and 7 patients respectively.

The average duration of symptoms before presentation was 5 months (range: 1 day to 10 years). Table 2 shows the distribution of patients according to the duration of symptoms at presentation.

The main presentation complaint was renal colic in 81 patients (79.4\%). Distribution of the patients according the reason for consultation was presented by Table 3. Forty patients (39.2\%) were referred from peripheral health centers, while six patients (5.9\%) were transferred from other units of University Hospital of Cotonou. Renal angle tenderness was present in 25 patients (24.5\%).

Imaging investigations which were performed include urinary tract ultrasound in 34 patients (33.3\%), combined IVU and ultrasoundin 19.6\%, IVU was performed in $18.7 \%$ and CT urography was performed in 9 patients (8.8\%). A total of 173 stones were identified. The average stone size was $12 \mathrm{~mm}$ with a range of $1 \mathrm{~mm}$ and $95 \mathrm{~mm}$. Three cases of bladder stones were recorded. In $66.7 \%$ of the cases (68 patients) single stone was found, while $20.6 \%$ of cases (21 patients) had two stones, and more than three stones were found in $12.7 \%$ of cases (13 patients). Stone 


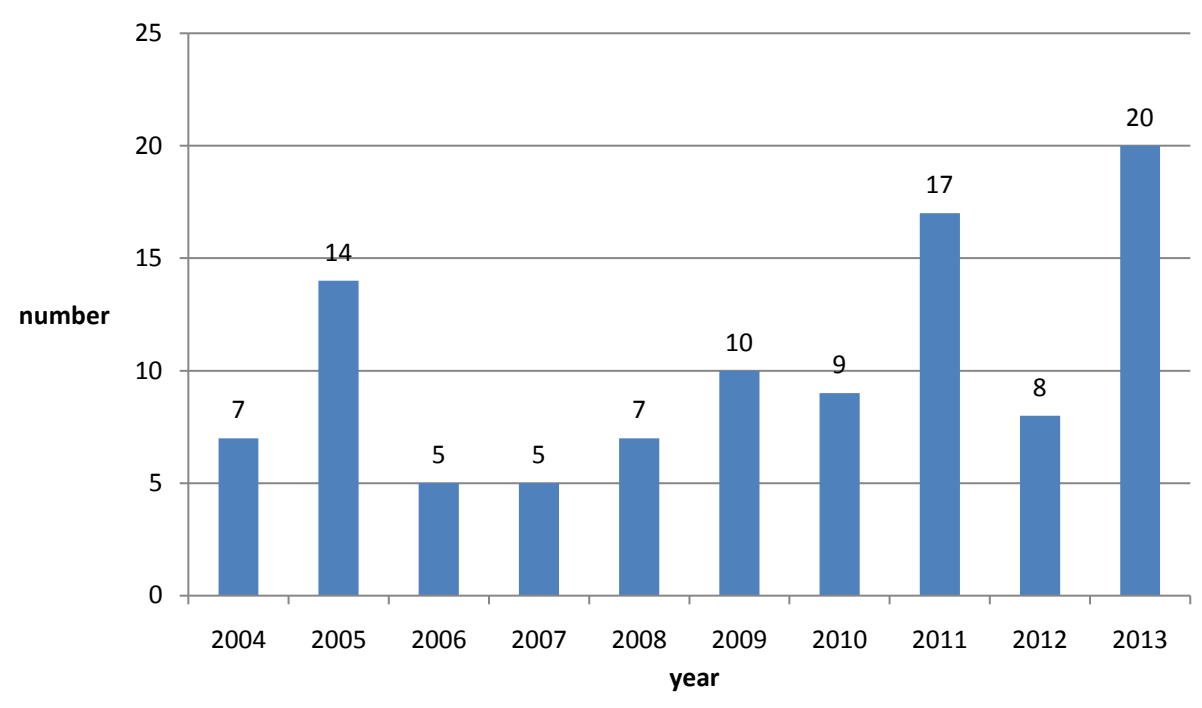

Figure 1. The distribution of the patients who were confirmed with urolithiasis according the year of hospitalization.

Table 1. Distribution of the patients according to age group.

\begin{tabular}{ccc}
\hline Age group (years) & Number & Percent (\%) \\
\hline$<15$ & 2 & 1.9 \\
$16-30$ & 25 & 24.5 \\
$31-45$ & 45 & 44.2 \\
$46-60$ & 21 & 20.6 \\
$61-75$ & 9 & 8.8 \\
Total & $\mathbf{1 0 2}$ & $\mathbf{1 0 0}$ \\
\hline
\end{tabular}

Table 2. Distribution of the patients according to consultation delay.

\begin{tabular}{ccc}
\hline Deadline of consultation & Number & Percent (\%) \\
\hline$<1$ month & 35 & 34.3 \\
1 months - 5 months & 24 & 23.5 \\
6 mouths - 1 year & 11 & 10.8 \\
1 year - 4 years & 24 & 23.5 \\
$\geq 5$ years & 8 & 7.8 \\
Total & $\mathbf{1 0 2}$ & $\mathbf{1 0 0}$ \\
\hline
\end{tabular}

Table 3. Distribution of the patients according to mean presentation of complaint.

\begin{tabular}{ccc}
\hline Mean presentation of complaint & Number (N = 102) & Percent (\%) \\
\hline Renal colic & 81 & 79.4 \\
Back pain & 42 & 41.2 \\
Dysuria & 18 & 17.6 \\
Burns urination & 18 & 17.6 \\
Hematuria & 16 & 15.7 \\
Nausea/vomiting & 15 & 14.7 \\
Fever renal colic & 15 & 14.7 \\
Obstructive anuria & 8 & 7.8 \\
Urinary tract infection & 7 & 6.9 \\
\hline
\end{tabular}


of the upper urinary tract accounted for $81.5 \%$ of cases. Distribution of the patients according to location of stone at radiography is shown in Table 4.

$5.7 \%$ of the patients have both lower and upper urinary tract lithiasis and $10 \%$ have bilateral stones. Urine microscopy, culture, and sensitivity was performed in $74.6 \%$ of cases; UTI was diagnosed in $37.3 \%$ of the cases and two-thirds of these cases cultured Escherichia coli. Renal failure was noted in 9 patients (8.8\%).

Open surgery was offered to patient with stone who could not be treated medically. Two patients underwent emergency nephrostomy. All patients were advice on dietary modification and were placed on symptomatic treatment including excessive water intake and use of non-steroidal drugs. Sixty-one patients (50.8\%) underwent open surgery. The different treatment modalities offered are listed in Table 5.

One hundred and sixteen (67.1\%) stones were extracted through open surgery. Among the patients who received medical therapy, 9 patients (8.8\%) expelled their stone.

The postoperative course was uneventful in $77.5 \%$ of the cases. Postoperative complications observed include surgical site infection in $15.7 \%$ of cases, macroscopic hematuria in $1.9 \%$ and epididymo-orchitis in $2.9 \%$ of cases. Seven patients (6.9\%) left hospital against medical advice. The postoperative clinical parameters and urinary tract imaging picked missed/residual stone $4.9 \%$ of cases. All patients were seen in the clinic between first to second week after discharged. The average hospital stay was 12 days and ranged from 1 day to 60 days.

\section{Discussion}

Urolithiasis is a common urological indication for admission in our center. The clinic leads mainly to hospitalization. Urolithiasisis a disease of the young patients as found in several studies. In our study, most patients (68.7\%) are within the age range of 15 to 45 years. Our data are consistent with the results of Kabore et al. [5] in Burkina Fasoand Daudon et al. [2] in France. Male gender is more affected in this study with male to female

Table 4. Distribution of the patients according to location of stone at radiography.

\begin{tabular}{ccccc}
\hline Location of stone & Male & Number (Sex) & Female & Total (\%) \\
\cline { 2 - 3 } Upper calix & 7 & 10 & $17(9.8)$ \\
Middle calix & 16 & 6 & $22(12.7)$ \\
Distal calix & 13 & 5 & $18(10.4)$ \\
Renal pelvis & 27 & 10 & $37(21.4)$ \\
Upper ureter & 10 & 14 & $24(13.9)$ \\
Middle ureter & 6 & 2 & $8(4.6)$ \\
Distal ureter & 17 & 10 & $27(15.6)$ \\
Bladder & 16 & 4 & $20(11.5)$ \\
Total & $\mathbf{1 1 2}$ & $\mathbf{6 1}$ & $\mathbf{1 7 3}(\mathbf{1 0 0})$ \\
\hline
\end{tabular}

Table 5. Distribution of the patients according management.

\begin{tabular}{|ccc|}
\hline Therapeutic modalities & Number & Percent (\%) \\
\hline Pyelolithotomy & 17 & 16.7 \\
Ureterolithotoy & 17 & 16.7 \\
Cystolithotomy & 16 & 15.7 \\
Nephrolithotomy & 9 & 8.9 \\
Nephrectomy & 2 & 1.9 \\
Medical treatment & 41 & 40.2 \\
Total & $\mathbf{1 0 2}$ & $\mathbf{1 0 0}$ \\
\hline
\end{tabular}


ratio of 2.2. Coulibaly et al. [6] found male to female ratio of 1.4. Diallo et al. [4] and Odzébé et al. [7] found male to female ratio of 3.3 and 3.2 respectively. Daudon [2] in his study also found male preponderance. Urolithiasis is one of the commonest cause of colicky loin pain. Past history of retroperitoneal surgery may be particularly important as they can induce inflammatory respond with healing with fibrosis that may occur cause extrinsic compression of the urinary tract and subsequent risk of urinarystasis and formation of upper tract urolithiasis. Synchronous occurrence of gall bladder stone and urolithiasis was noted in several series; in our study, we found $5 \%$. Metachronous gall bladder stone is estimated at about $50 \%$ with a statistically higher risk in the first 5 years following the discovery of the first urolithiasis as reported in several series [8] [9]. Renal colic was the main presenting complaint in our study. This is similar to report by Diallo et al. in Guinea [4]. The average consultation time was 35 months in the series of Diallo et al. [4]; it was 5months in our series. This period long enough is explained by the made the first in augural crisis sometimes gives spontaneously after a few minutes and the time between the onset of the crisis and the second opening is long enough which causes patients to consult in case complications of gallstone disease (anuria, renal colic, hyperalgicor feverish).

Urinary stone may be caused by urinary tract infection (UTI). It is the third leading cause of urolithiasis [10]. The most commonly implicated organism are the urea splitting bacteria such as Proteus species, Klebsiella pneumoniae, Pseudomonas sp., and Staphylococcus aureus [11].

In this study, urine microscopy, culture and sensitivity test was positive for bacteria in $37.3 \%$ of cases with a predominance of $E$. coli. This is similar to observation made by Diallo et al. [4] in their study. They found urinary tract infection in $88.5 \%$ of cases and the presence of $E$. coli in $33.3 \%$ of cases.

Although CT scan is the gold standard radiologic investigation in patient with suspected urolithiasis, most of our patient had ultrasonography and IVU of the urinary tract due to non availability or afordability of CT scan.

Open surgery was the main route of surgical removal. It was performed in $50.8 \%$ of our patients, and about $67.1 \%$ ofall the stones were extracted via this modality of treatment. In a study by Kabore et al. [3] in Ouagadougou, 32.3\% of patients underwent open surgery. Similarly, all patients in a study by Odzébé [7] in Brazzaville underwent open surgery. Open surgery still remains the primary route of stone extraction in many developing countries despite the advent of modern methods of stone extraction. The advent of endoscopy has revolutionized treatment of urolithiasis [12] [13]. However, there is still place for open surgery in large or complex stones. The committee on stones of the French Association of Urology (AFU) in 2013 [14] has given guidelines regarding therapeutic approach to upper urinary tract stones. Pyelolithotomy and ureterolithotomy were the commonest (33.4\%) surgical procedures performed. Nephrolithotomy came in $4^{\text {th }}$ position and constitute $8.9 \%$ of the open surgeries, while cystolithotomy is the $3^{\text {rd }}$ accounting to $15.7 \%$ of open surgeries. This may reflect the recent trend in distribution of stone, patient form upper tract stone more the lower tract stone. Very often, calyceal stones (especially upper and middle calyceal stone) are not obstructive are small in diameter, they can be easily passed with excessive water intake. Kabore et al. [3] had found in their study that nephrolithotomy was the commonest surgical procedure (55\% of cases); ureterolithotomy was done in $13.7 \%$ of the cases; and pyelolithotomy in $8.4 \%$ of cases. After ureterolithotomy, patients may benefit from ureteric stent and drainage of the retroperitoneal space 3 - 5 days. The postoperative courses in our series were uneventful in $77.5 \%$ of cases. Complications noted were predominantly surgical site infection. This is similar to report made by other African studies [3] [15]. Nephrectomy was done to two patients due to pyonephrosis with significant renal parenchymal destruction. This is a complication of obstructive uropathy that should be prevented by early diagnosis and appropriate treatment because it can lead to life-threatening sepsis.

The average hospital stay was 12 days. The average duration was 6.5 days in the study of Kaboré et al. [3]. The prolonged hospital stay in our study is due to patient preference to stay until when their wounds healed following surgical site infection. In addition, some patients stay long because they could not settle their hospital bill.

\section{Conclusion}

Management of urolithiasis remains a challenge for our health services. The diagnosis is easily made with the aid of radiological imaging, but presentation is usual. The introduction of endoscopy in the management of urinary stones is now the standard. There is still place for open surgery in some staghorn and complex stones.

\section{References}

[1] Daudon, M. and Dore, B. (1999) Cristallographie des calculs urinaires: Aspects néphrologiques et urologiques. Ency- 
clopédie Médico-Chirurgicale (Elsevier, Paris) Néphrologie-Urologie, 104-A-25, 1-17.

[2] Daudon, M., Traxer, O., Lechevallier, E. and Saussine, C. (2008) Épidémiologie des lithiases urinaires. Progrès en Urologie, 18, 802-814. http://dx.doi.org/10.1016/j.purol.2008.09.029

[3] Kabore, F.A., Kambou, T., Zango, B., Ouattara, A., Paré, A., Simporé, M., et al. (2013) Analyse retrospective du traitement chirurgical des lithiases urinaires au CHU Yalgado Ouedraogo de Ouagadougou (Burkina Faso). Revue Africaine d'Urologie et d'Andrologie, 1, 18-23.

[4] Diallo, A., Bah, I., Bah, M.D., Bah, O., Guirassy, S., Baldé, S., et al. (2008) Prise en charge de la lithiase du haut appareil urinaire au CHU de Conakry: Analyse rétrospective de 54 cas. African Journal of Urology, 14, 232-239.

[5] Kaboré, F.A., Kambou, T., Zango, B., Ouattara, A., Simporé, M., Lougué/Sorgho, C., et al. (2013) Épidémiologie d'une cohorte de 450 lithiases urinaires au CHU Yalgado Ouédraogo de Ouagadougou (Burkina Faso). Progrès en Urologie, 23, 971-976. http://dx.doi.org/10.1016/j.purol.2013.04.014

[6] Coulibaly, G., Zoungrana, W., Sapo, C. and Lengani, A. (2011) Néphrolithiase dans un poste de consultation externe de néphrologie à Ouagadougou. Medécine d'Afrique noire, 58, 461-466.

[7] Odzebe, A.S.W., Bouya, P.A., Berthe, H.J.G. and Omatassa, F.R. (2010) Open Surgery of the Urinary Tract Calculi at the University Hospital of Brazzaville: Analysis of 68 Cases. Mali Medical, 25, 32-35.

[8] Hesse, A., Brändle, E., Wilbert, D., Köhrmann, K.-U. and Alken, P. (2003) Study on the Prevalence and Incidence of Urolithiasis in Germany Comparing the Years 1979 vs. 2000. European Urology, 44, 709-713. http://dx.doi.org/10.1016/S0302-2838(03)00415-9

[9] Ulmann, A., Clavel, J., Destrée, D., Dubois, C., Mombet, A. and Brisset, J.M. (1991) Natural History of Renal Calcium Lithiasis. Data Obtained from a Cohort of 667 Patients. Presse Médicale, 20, 499-502.

[10] Blair, B. and Fabrizio, M. (2000) Pharmacology for Renal Calculi. Expert Opinion on Pharmacotherapy, 1, $435-441$. http://dx.doi.org/10.1517/14656566.1.3.435

[11] Daudon, M., Jungers, P. and Lacour, B. (2004) Clinical Value of Crystalluria Study. Annales de Biologie Clinique, 62, 379-393.

[12] Tawfiek, E.R. and Bagley, D.H. (1999) Management of Upper Urinary Tract Calculi with Ureteroscopic Techniques. Urology, 53, 25-31. http://dx.doi.org/10.1016/S0090-4295(98)00462-2

[13] Hecht, S.L. and Wolf, J.S. (2013) Techniques for Holmium Laser Lithotripsy of Intrarenal Calculi. Urology, 81, 442445. http://dx.doi.org/10.1016/j.urology.2012.11.021

[14] Chabannes, É., Bensalah, K., Carpentier, X., Bringer, J.-P., Conort, P., Denis, É., et al. (2013) Prise en charge urologique des calculs rénaux et urétéraux de l'adulte. Mise au point du Comité lithiase de l'Association française d'urologie (CLAFU). Aspects généraux. Progrès en Urologie, 23, 1389-1399. http://dx.doi.org/10.1016/j.purol.2013.08.315

[15] Ouattara, Z., Effoé, A., Tembely, A., Sanogo, Z., Yena, S. and Doumbia, D. (2004) Etude de 72 cas de lithiases du haut appareil urinaire au service d'urologie de l’hopital du Point G. Mali Méd. 
Scientific Research Publishing (SCIRP) is one of the largest Open Access journal publishers. It is currently publishing more than 200 open access, online, peer-reviewed journals covering a wide range of academic disciplines. SCIRP serves the worldwide academic communities and contributes to the progress and application of science with its publication.

Other selected journals from SCIRP are listed as below. Submit your manuscript to us via either submit@scirp.org or Online Submission Portal.
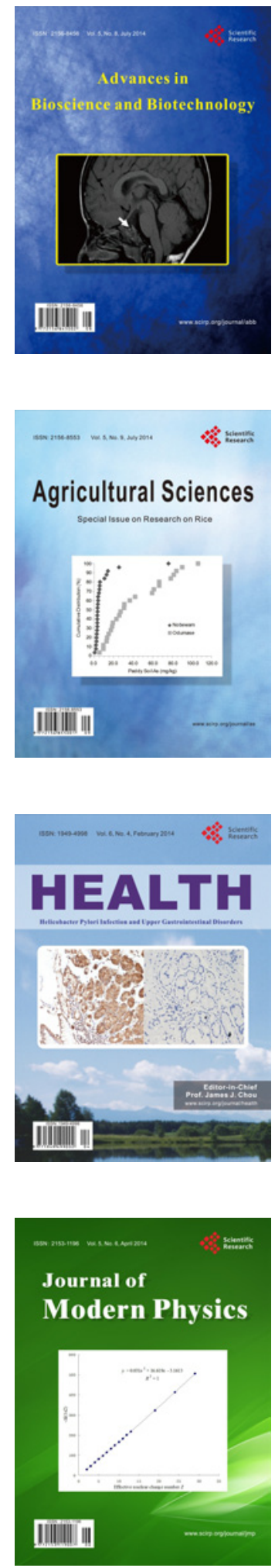
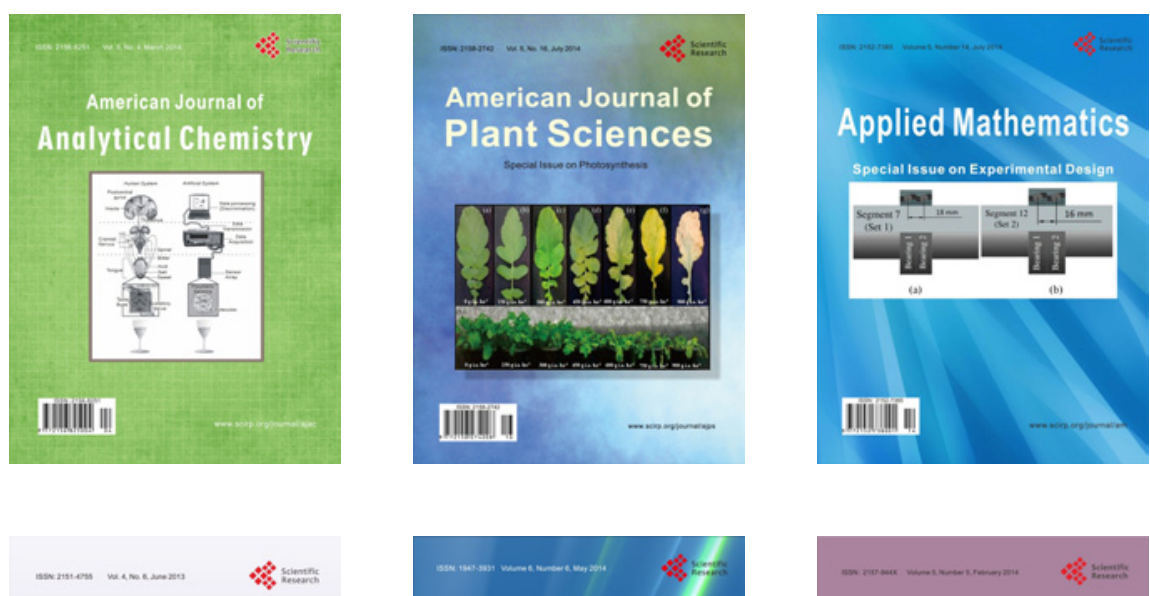

Creative Education
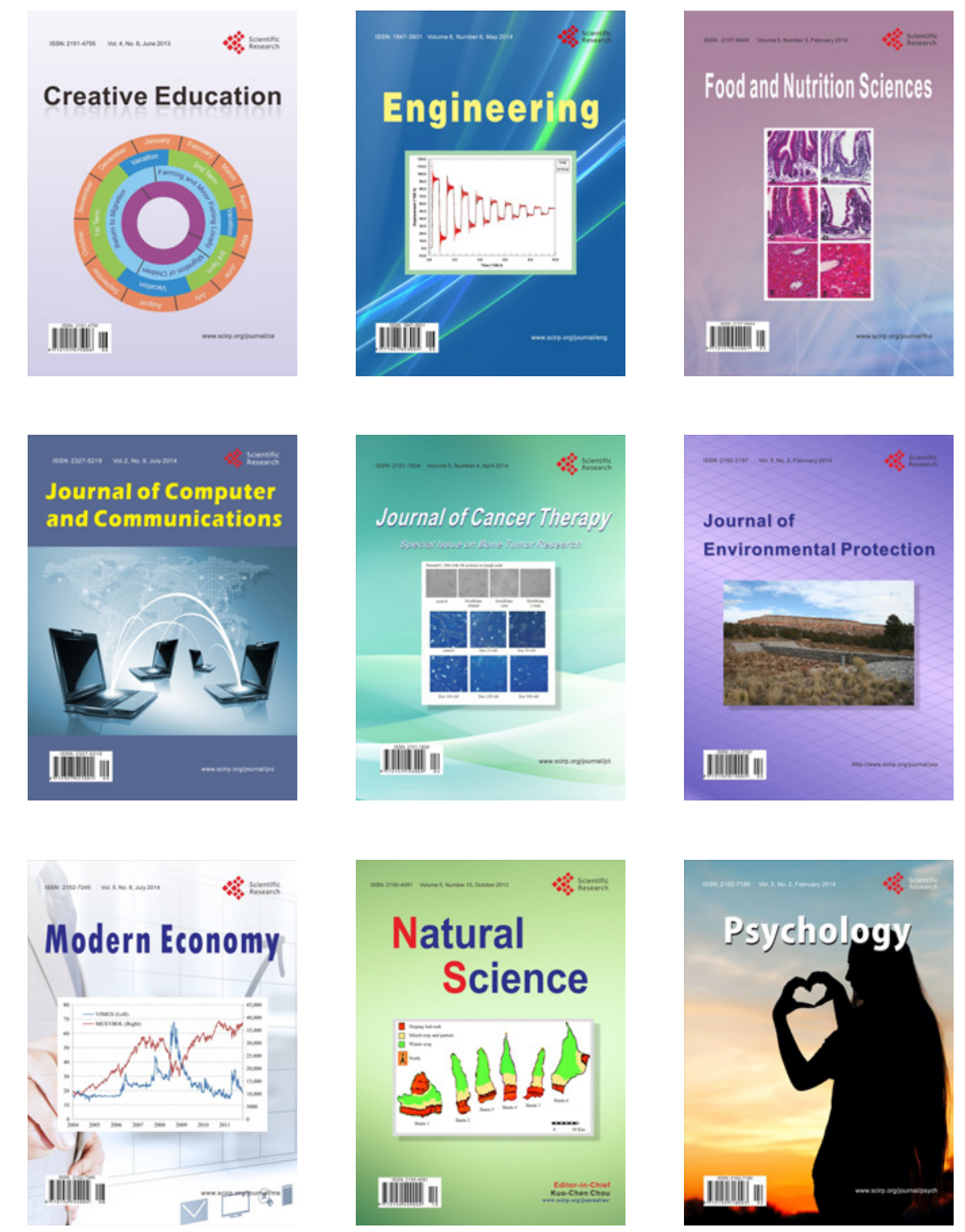